\title{
Stephen A'Court interviewed by Peter Cleave
}

Stephen A'Court has worked in dance photography in New Zealand for a number of years. His work is very highly regarded. Peter Cleave asked Stephen some questions;

\section{What are you looking for?}

1. Ideally, a sense of movement in a completely still image. The viewer sees a very still and sharp image, but it's obvious that the body is on its way from one place to another.

2. I also look for the peak moment, when the dancer is momentarily completely on balance; or when leaping the dancer is at that point where she is no longer going up but is yet to start to come down.

3. I'm looking for nice technique, especially if I'm photographing classical ballet.

4. Expression \& emotion from the dancer, that tells the viewer about the feeling of the dance.

5. Moments of physical contact between two or more dancers.

6. Taking photos on stage, covering a performance, I'm looking to create a record of the complete work as much as I possibly can, find those peak moments, and make sure every dancer is covered! I'm interested in the staging - recording the costumes and the lighting state. So I go wide to see the whole stage, and I zoom in very close to individuals. A lot to think about in a short time. I shoot very quickly. I shoot hundreds or even thousands of frames, and edit very heavily. 


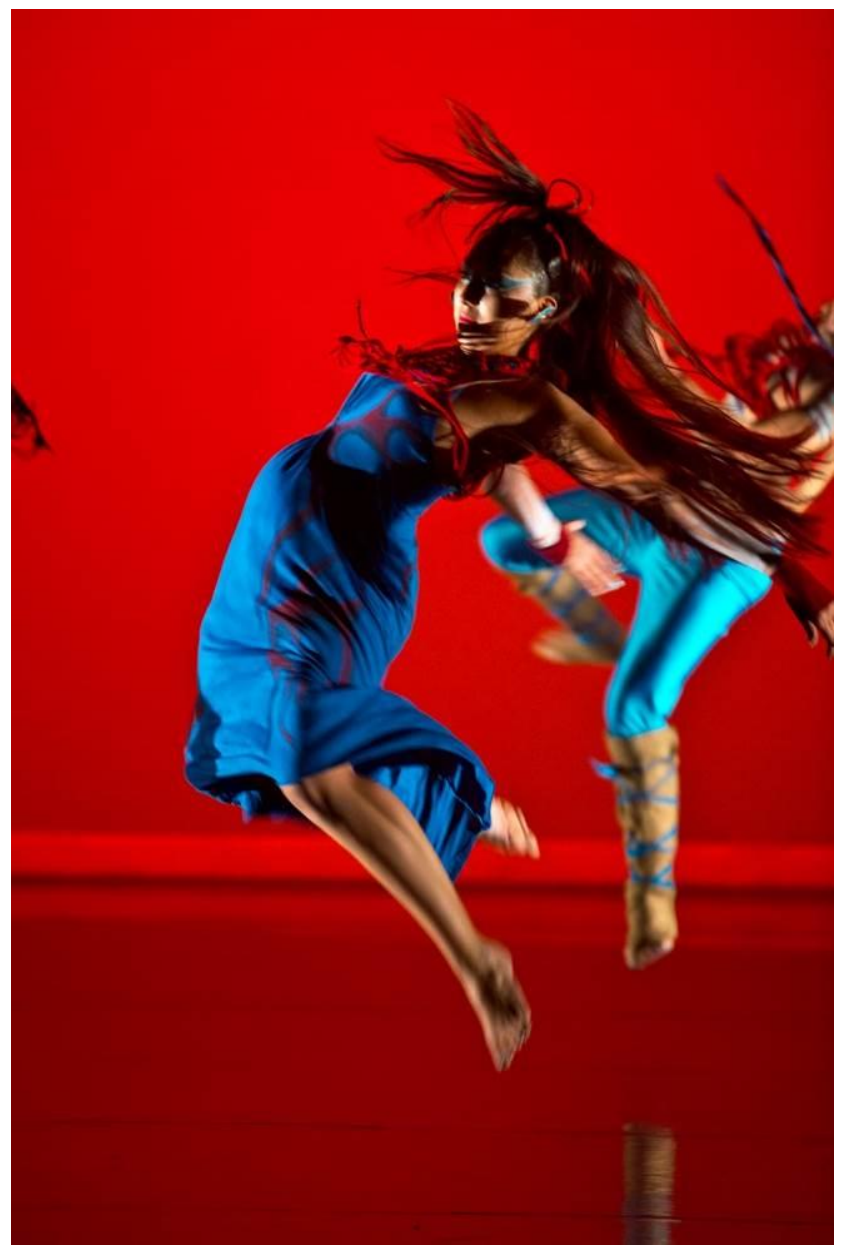

Photo: Stephen A'Court

Pictured: Dancing Earth Company

2 Is it the dance or the dancer that attracts you? Both, equally. (They are intertwined, of course.) The style of dance makes a huge difference - slow or fast, classical or contemporary, or a stage full of people or a pas de deux. All have their challenges. Photographically I prefer physically 
strong contemporary styles. But the dancer is crucial, to allow me to capture an emotional state. I have worked with many. many dancers over the years, but there are a handful who I have worked with time after time, for their emotional commitment and their sometimes wild passion!

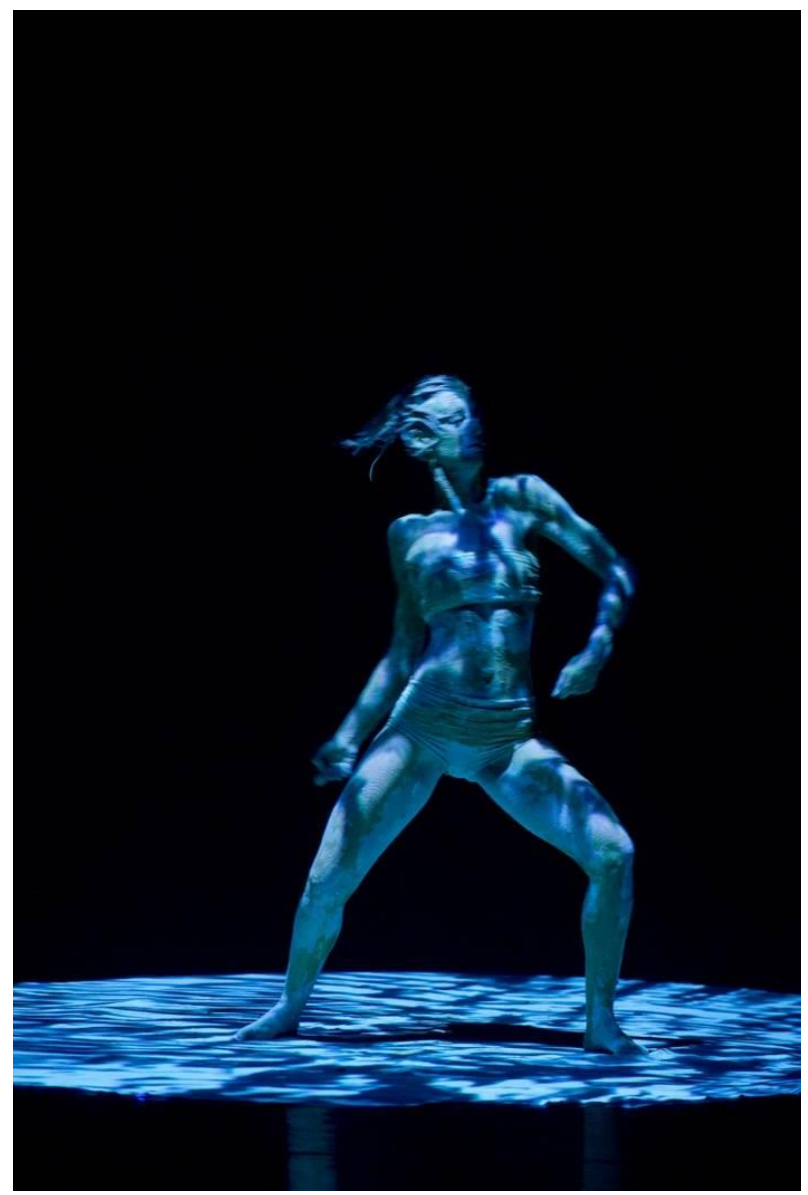

Photo: Stephen A'Court

Pictured: Louise Potiki Bryant 
3 How do you relate to the dancer that you photograph? Do you talk often and easily or do you leave a distance between yourself and your subject?

Yes, a rapport with a dancer is important, when working in the studio. Ideally I speak quietly, and let the dancer think. What happens in their head, and their concentration, is one of the most important things. Dancing for the camera is an intellectual exercise as much as a physical one. I almost always work with a choreographer or artistic director - and I try to keep it a warm and happy atmosphere - and I try to keep the set as empty of other people, and as quiet, as possible.

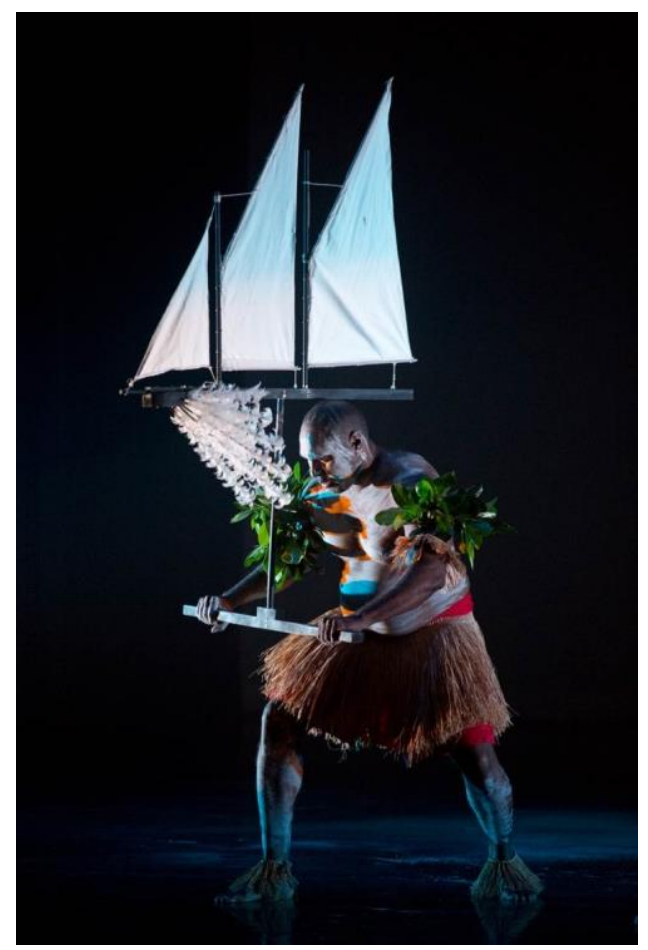

Photo: Stephen A'Court

Pictured: Masepah Banu, Baiwa Dance Company 
4 What about other photographers including people taking videos and pictures on hand held devices? Are you taking photos of people taking photos, holding up lit cameras in the dark and variations on these things?

I have no problem working amongst other photographers professional or otherwise, for stage work. Luckily I most often work at dress rehearsals where there are no other people, or very few people. I shot alongside a fantastic photographer, Jose G Cano, recently, at the NZSD rehearsals, and I enjoyed so much shooting alongside him and talking about the work we do

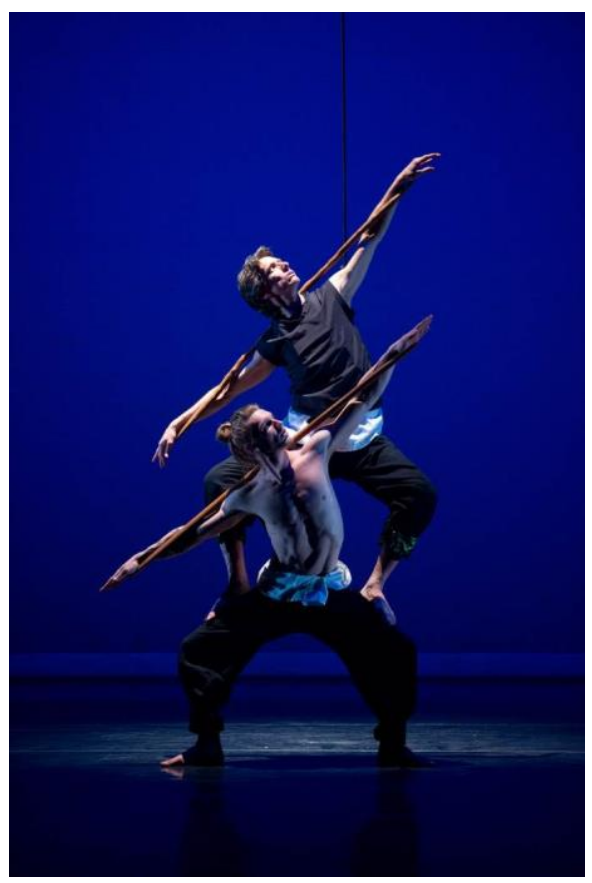

Photo: Stephen A'Court

Pictured: Tanemahuta Gray and Luke Hanna, Merenia Gray Dance Theatre 


\section{5 what are the qualities you would look for in a good arts photographer?}

1. Team work. When working for a specific production - rather than doing my own work - I'm part of the team which tells the story of that show. The director and the marketing people set the overall theme and look of all that. I fit in. 2. Interest and empathy with the life of the artist. I don't feel I need to know everything about an art form I photograph. I just have to have an empathy for the work, and the life of the people who created and present the work. I work in the theatre, in dance, and I photograph gallery art - without any background in these areas at all, but with a deep interest.

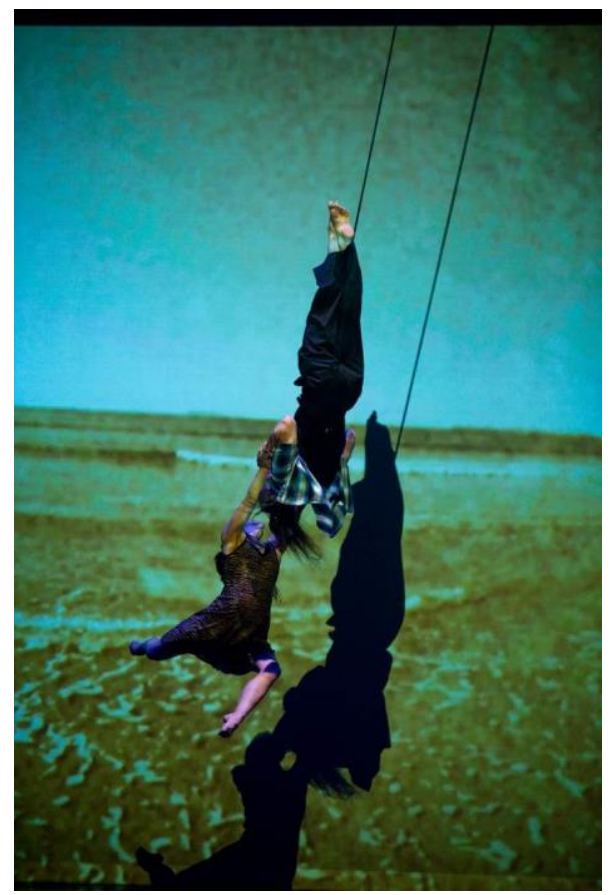

Photo: Stephen A'Court

Pictured: Jana Castillo and Luke Hanna, Aotearoa Aerial Theatre Company 
6 Who are your exemplars in the world of photography? In NZ, John McDermott and Ross Brown. Internationally, R J Muna, in San Francisco USA.

http://www.nzdc.org.nz/node/john-mcdermott/ http://www.johnmcdermottphotography.co.nz

Ross Brown's work for The Royal NZ Ballet http://www.matchphotographers.com/ross-brown/+physical/1/thumbs/

or http://www.matchphotographers.com

http://rimuna.com/galleries/images/dance/showcase/

http://rjmuna.com/galleries/

San Francisco USA photographer

\section{Your work is permanent and not fleeting like a dance performance. What does this mean to you?}

It means a great deal to me. When the performance is done, the visual record is all that remains. As time goes by, I am creating an archive which I believe gets more valuable, in an artistic sense. I have photographed actors on stage who are no longer living, and I've photographed now-established actors early in their careers. I have photographed dancers at the peak of their careers, who've now retired. So I've captured something which is never coming back, will never be seen again, except in my archive of photos! 


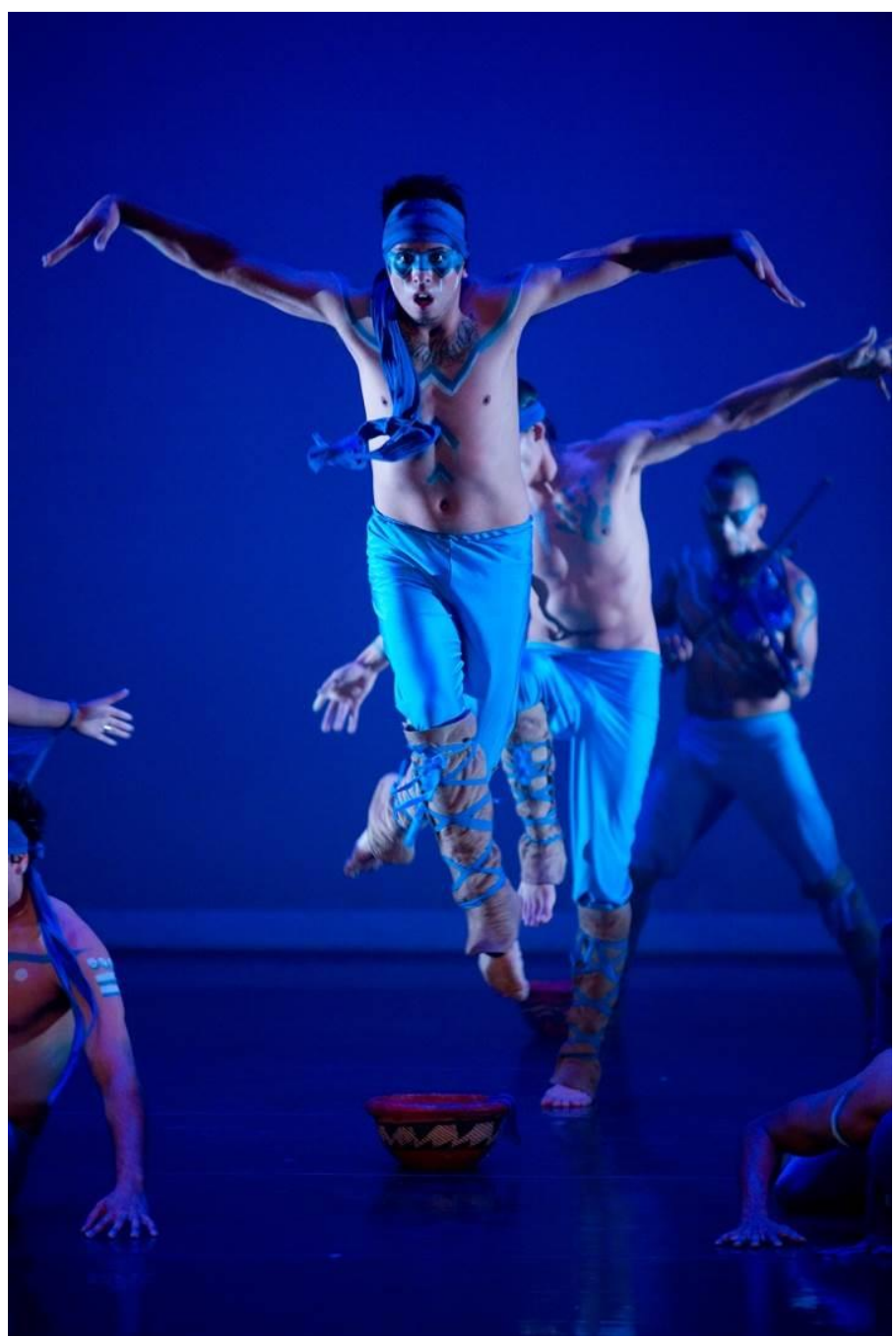

Photo: Stephen A'Court

Pictured: Dancing Earth Company 


\section{Are you like a portrait artist?}

1. Of course. If a portrait photographer aims to capture personality and emotion - I am doing that with dance photography. No one else on the planet looks as good as a dancer - so a lot of it is inevitably about form and shape but even then, dance photography is mostly about the human and personal. It's a mistake to look at anyone as an object, and dancers are sometimes seen that way.

2. Dance photography is just photography. On one level it's all about lighting, composition, capturing a nice moment, and so on. The thing that separates dance is: it's so beautiful, more than anything I can think of. But I light people and work with them in just the same way, no matter the circumstances whether it's art photography or commercial photography. 


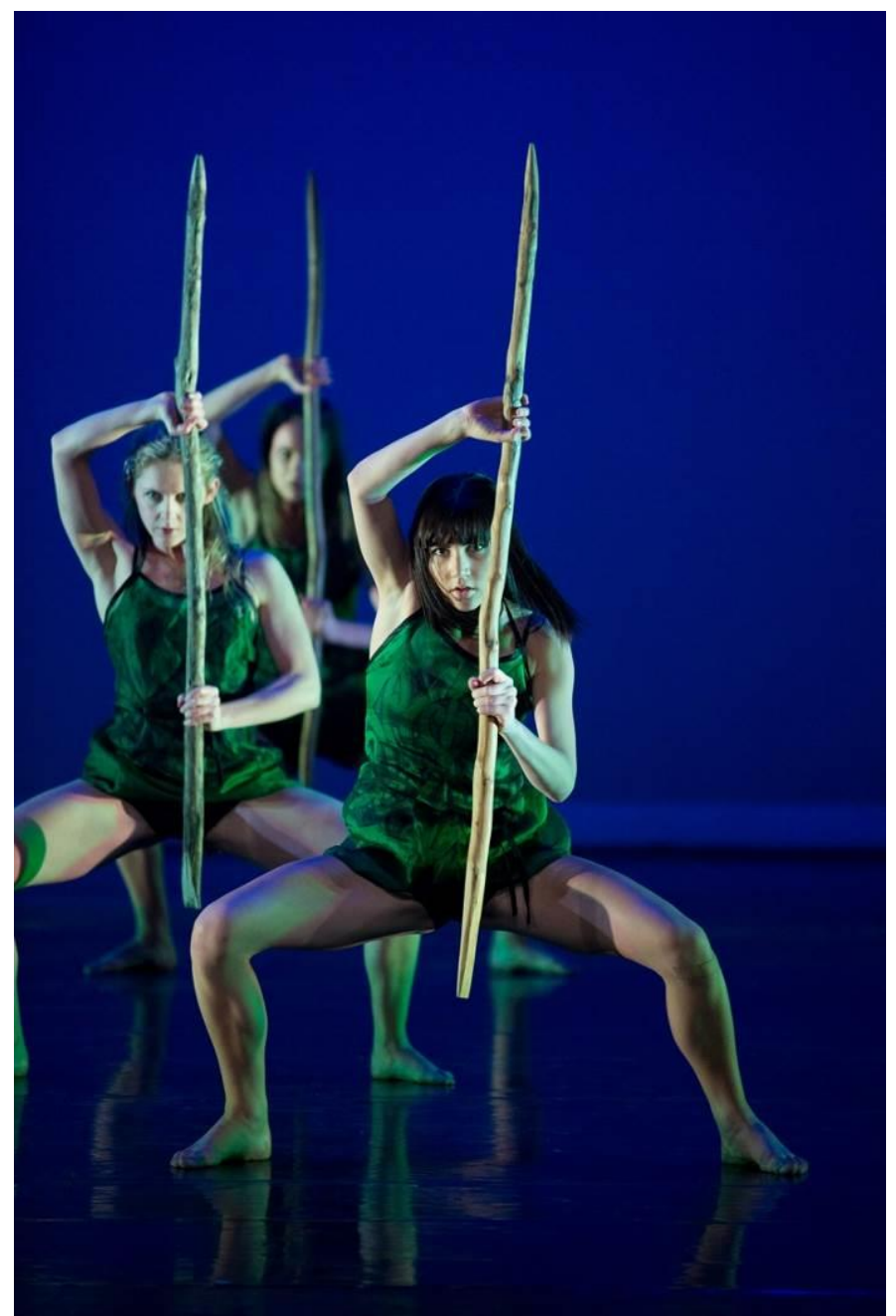

Photo: Stephen A'Court

Pictured: Anita Hunziker and Alice McCann, Merenia Gray Dance Theatre 
9 What kind of ground rules do you set out with management?

Very few. I assert copyright in my images, but I am conscious that many others have intellectual property in the dance and the performance I'm photographing.

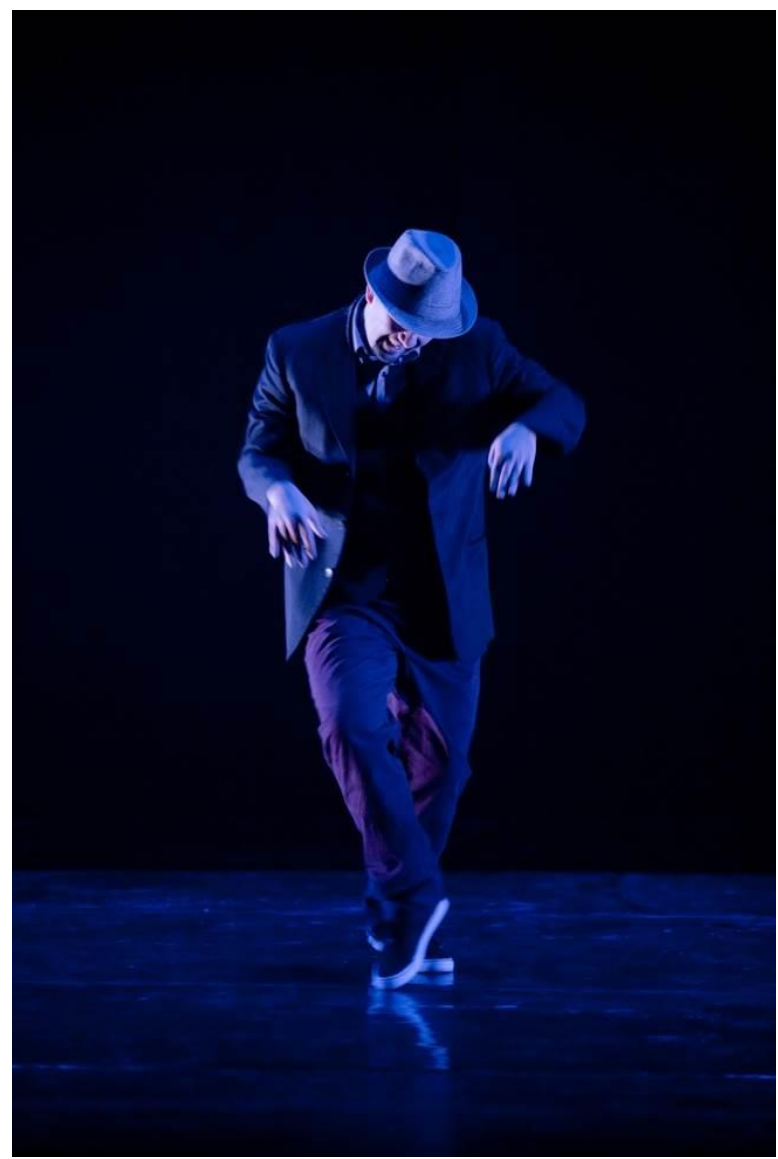

Photo: Stephen A'Court

Pictured: Future Fame 


\section{What kind of ground rules do management set out for you? For example, do you go over photos before publication?}

Yes, most often. Images are approved. Dance companies are extremely conscious of their public image. And the differences between acceptable technique and not can be very small. Some artistic directors are notoriously difficult to please. But that's all part of the system. On other occasions, the people I'm working for are not so strict, and I am simply careful about what I edit, and I always allow the people involved to remove images from my selection, for any reason.

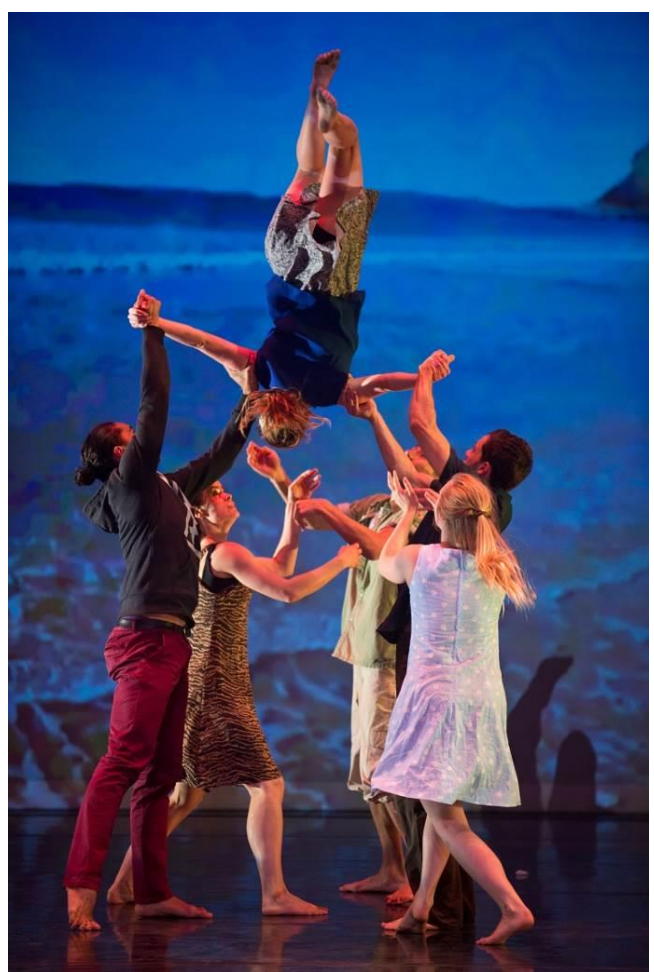

Photo: Stephen A'Court

Pictured: Aotearoa Aerial Theatre Company 


\section{Are you comfortable with the rules and conventions around dance photography?}

Yes, to a degree. I will always be learning more, to fully understand the conventions. After 20 years I'm still learning about what's considered nice technique. Am I a slow learner? There's a lot to learn. If photographing a show, I'm always conscious that I'm doing this for the record, for the dance company, and their needs are uppermost. In my own more personal work, the rules are perhaps relaxed, but all the dancers I work with are connected or contracted with a dance company, and are recognisable, and in some way whenever they are photographed it reflects on that company. So I'm conscious of the wider dance community.

\section{What stands out in your mind about Kowhiti Atarau 2013?}

1. How recognisable the international dance was, from a photographic-coverage point of view. It sort of proves dance is universal. The underling dance ideas were quite different from anything I'd seen - in the case of the dancers from the USA and from Torres Strait - but capturing the moves I was looking at just the same things as always.

2. The fabulous colours and costumes from NZ and around the world. Visually, as a whole, it was so stimulating and vibrant. Every piece was fabulous, to my eye. Highlights were Tanemahuta Gray flying through the sky on wire, Louise Potiki Bryant covered in mud and moving in a blue circle of light, and the amazing red and blue colours and dramatic shapes of Rulan Tangen and the Dancing Earth company from the USA. 


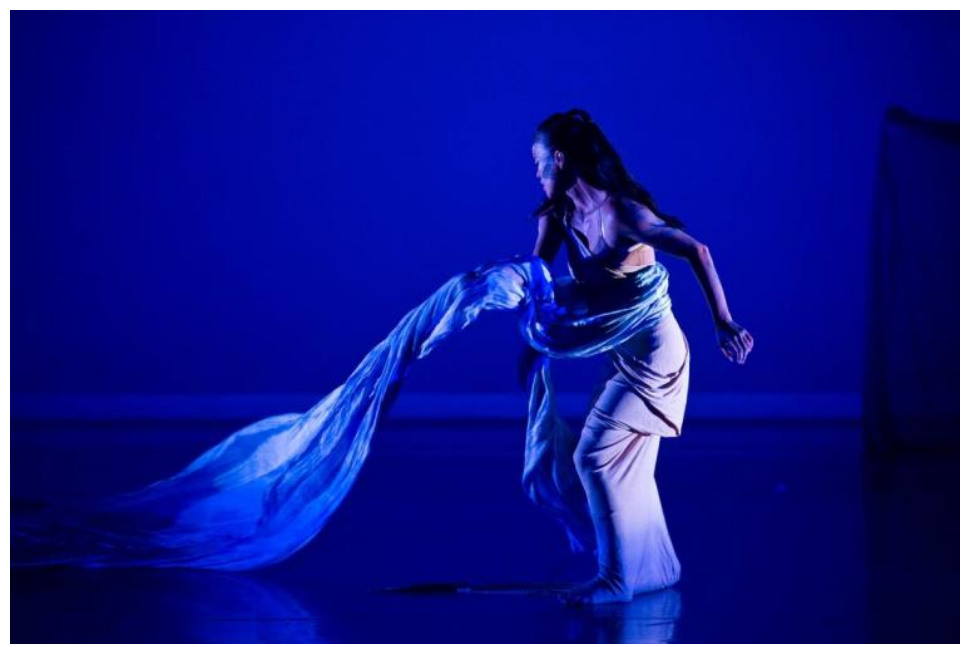

Photo: Stephen A'Court

Pictured: Rulan Tangen, Dancing Earth Company 